\title{
Hubungan Riwayat Reproduksi dengan Tumor Payudara pada Perempuan Usia Muda di Indonesia (Analisis Riset PTM 2016)
}

\author{
The Association of Reproductive History with Breast Tumor in Young Women \\ in Indonesia (Analysis of Riset PTM 2016)
}

\author{
Rizqy Fauzia Ahsani, Putri Bungsu Machmud* \\ Departemen Epidemiologi, Fakultas Kesehatan Masyarakat Universitas Indonesia \\ (*putri.bungsu10@ui.ac.id)
}

\begin{abstract}
ABSTRAK
Kejadian tumor payudara meningkat setiap tahunnya di Indonesia. Saat ini, tumor payudara tidak hanya menyerang pada usia lanjut, namun juga usia muda. Beberapa penelitian menunjukkan faktor reproduksi berhubungan dengan tumor payudara. Penelitian ini bertujuan mengetahui hubungan riwayat reproduksi dengan kejadian tumor payudara pada perempuan usia muda di Indonesia tahun 2016. Penelitian ini menggunakan desain studi cross sectional dan dilakukan pada bulan Desember 2018-Januari 2019 di Fakultas Kesehatan Masyarakat Universitas Indonesia menggunakan data sekunder dari Riset PTM 2016. Populasi dalam penelitian ini adalah semua responden Riset PTM 2016. Sampel penelitian berjumlah 14.891 responden (total sampling) berusia di bawah 40 tahun dalam Riset PTM yang memenuhi kriteria inklusi dan eksklusi. Variabel yang diteliti dalam penelitian ini yaitu variabel independen yang terdiri dari usia menarche, usia pertama melahirkan, status-kawin, riwayat menyusui, riwayat penggunaan kontrasepsi hormonal; dan variabel dependen yaitu kejadian tumor payudara. Analisis data menggunakan uji kuadrat dan uji regresi logistik. Hasil penelitian menunjukkan adanya hubungan usia menarche $(\mathrm{OR}=1,269)$, status perkawinan $(\mathrm{OR}=1,353)$, riwayat menyusui $(\mathrm{OR}=1,295)$, dan riwayat kontrasepsi lebih dari 5 tahun $(\mathrm{OR}=1,113)$ dengan kejadian tumor payudara pada perempuan usia muda di Indonesia.
\end{abstract}

Kata kunci: Tumor, payudara, menarche, kontrasepsi, Indonesia

\section{ABSTRACT}

The incidence of breast tumor increases every year in Indonesia. At present, breast tumors do not only attack the elderly, but also at young age. Some studies show factors associated with breast tumors. Therefore, this study aimed to study the association of the reproductive history with tumor incidence in young women in Indonesia in 2016. This study used a cross-sectional study design and was conducted in December 2018-January 2019 in the Faculty of Public Health of Universitas Indonesia using secondary data from the Riset PTM 2016 (Non-communicable Disease Research 2016). The population in this study were all respondents of the 2016 PTM Research. The sample was 14,891 respondents (total sampling) aged under 40 years who meet the inclusion and exclusion criteria. The variables used in this study were independent variables consisting of age of menarche, age of first birth, marital status, breasfeeding history, the use of hormonal contraception; and the dependent variable is the incidence of breast tumors. The data was analyzed by chi square and logistic regression test. The results showed an association between menarche age $(O R=1,269)$, marital status $(O R=1,353)$, breasteeding history $(O R=1,295)$, and the use of hormonal contraception more than 5 years $(O R=1,113)$ with breast tumors in young women in Indonesia.

Keywords:Tumor, breast, menarche, contraception, Indonesia 


\section{PENDAHULUAN}

Tumor atau neoplasma secara umum berarti benjolan yang disebabkan pertumbuhan sel abnormal dalam tubuh. Pertumbuhan tumor dapat bersifat ganas (maligna) atau jinak (benigna). ${ }^{1}$ Kanker payudara merupakan tumor ganas payudara yang mengacu pada kanker yang berasal dari jaringan payudara (duktus, lobulus, dan jaringan penunjang lainnya). ${ }^{2}$ Kanker payudara adalah kanker paling umum pada wanita dan penyebab utama kematian akibat kanker di seluruh dunia. ${ }^{3}$

Penelitian Anyikam et al, di Nigeria Timur menunjukkan dari 1.050 spesimen payudara yang diteliti, 722 kasus $(68,8 \%)$ merupakan tumor jinak. ${ }^{4}$ Penelitian sebelumya yang dilakukan di Thailand, menunjukkan 1.846 dari 2.532 jaringan yang dilakukan biopsi $(72,9 \%)$ menderita tumor jinak payudara di usia sebelum 40 tahun. ${ }^{5}$ Jumlah perempuan yang dideteksi tumor payudara di Indonesia berdasarkan hasil pemeriksaan payudara klinis (Sadanis) meningkat tiap tahunnya. Prevalensi tumor payudara pada tahun 2015 sebesar 1,8 per 100.000 perempuan usia $30-50$ tahun. Kemudian prevalensi kasus tumor payudara meningkat pada 2016 menjadi 3,3 per 100.000 perempuan usia 30-50 tahun. Kasus tumor payudara meningkat drastis menjadi 21,3 per 100.000 perempuan $30-50$ tahun pada tahun 2017 .

Usia muda didefinisikan sebagai usia di bawah 40 tahun menurut The European Society of Breast Cancer Specialist (EUSOMA). Menurut Cardoso, usia di bawah 40 tahun memiliki permasalahan kesuburan, kehamilan, dan menyusui yang berbeda dengan usia premenopause. ${ }^{7}$ Saat ini tumor payudara juga menyerang perempuan usia muda. Berdasarkan penelitian Azim, di negara berkembang seperti Afrika dan Timur Tengah, proporsi penderita tumor payudara ganas di bawah usia 40 tahun mencapai $20 \%$, lebih tinggi dibandingkan negara-negara maju. ${ }^{8}$ Di Indonesia, berdasarkan hasil riset PTM 2016 menunjukkan hampir setengah (kurang lebih 47\%) dari prevalensi tumor payudara di perkotaan Indonesia berusia di bawah 40 tahun. ${ }^{9}$

Beberapa penelitian telah membuktikan bahwa tumor payudara jinak merupakan faktor risiko terjadinya kanker payudara. Menurut Castells, risiko terjadinya kanker payudara pada perempuan yang memiliki tumor payudara sebesar 2,51 kali dari pada perempuan tanpa tumor payudara. ${ }^{10}$ Berbagai faktor risiko dapat memengaruhi tumor payudara seperti genetik, lingkungan, status sosio ekonomi, usia menarche, usia pertama melahirkan, status kawin, riwayat menyusui, riwayat penggunaan kontrasepsi hormonal. Namun dalam penelitian ini, berfokus pada hubungan riwayat reproduksi (usia menarche, usia pertama melahirkan, status kawin, riwayat menyusui, riwayat penggunaan kontrasepsi hormonal) agar dapat dilakukan pencegahan dan intervensi mengenai riwayat reproduksi. Atas dasar tersebut, penulis tertarik untuk mengetahui hubungan riwayat reproduksi (usia menarche, usia pertama melahirkan, status-kawin, riwayat menyusui, riwayat penggunaan kontrasepsi hormonal) dengan kejadian tumor payudara pada perempuan usia di bawah 40 tahun di Indonesia menggunakan data Riset PTM 2016.

\section{BAHAN DAN METODE}

Penelitian ini menggunakan pendekatan observasional analitik dengan metode kuantitatif menggunakan desain studi cross sectional. Penelitian dilakukan pada bulan Desember 2018 sampai Januari 2019 menggunakan data Riset PTM 2016 yang dilakukan di daerah perkotaan di Indonesia pada 2016. Penelitian ini telah lulus kaji etik dari Komite Etik FKM UI pada tanggal 31 Desember 2018 dengan nomor surat 810/UN2. F10/PPM.00.02/2018. Populasi dalam penelitian ini adalah semua responden pada Riset PTM 2016. Sementara, sampel dalam penelitian ini adalah perempuan dewasa muda usia di bawah 40 tahun di Indonesia yang menjadi sampel dalam Riset PTM 2016 dan memenuhi kriteria inklusi usia di bawah 40 tahun yang melakukan pemeriksaan Sadanis dan mempunyai data lengkap sesuai dengan variabel penelitian dan kriteria eksklusi yang memiliki nilai ekstrem pada variabel usia menarche, usia pertama melahirkan, dan lama penggunaan kontrasepsi. Dari 43.948 responden riset PTM 2016, 14.891 responden eligibel menjadi sampel penelitian. Peneliti menggunakan total sampling yang eligibel untuk meningkatkan presisi hasil penelitian. ${ }^{11}$ Analisis dilakukan secara univariat, bivariat, hingga multivariat. Analisis multivariat menggunakan regresi logistik untuk mengetahui variabel independen mana yang paling ber- 
hubungan dengan variabel dependen.

Variabel yang diteliti yaitu riwayat reproduksi (usia menarche, usia pertama melahirkan, status kawin, riwayat menyusui, riwayat penggunaan kontrasepsi hormonal), dan kejadian tumor payudara. Variabel tumor payudara dikelompokkan menjadi hasil positif pada pemeriksaan payudara klinis (Sadanis) dan hasil negatif. ${ }^{9}$ Usia menarche dikelompokkan menjadi $<12$ tahun dan $\geq 12$ tahun. ${ }^{12,13}$ Status perkawinan dikategorikan menjadi tidak kawin dan kawin. ${ }^{14}$ Usia pertama melahirkan dikategorikan menjadi nullipara/ belum pernah melahirkan, $>30$ tahun, dan $\leq 30$ tahun. ${ }^{15}$ Riwayat menyusui dikelompokkan menjadi menyusui dan tidak menyusui. ${ }^{11}$ Dan riwayat kontrasepsi hormonal dikelompokkan menjadi $>5$ tahun, $\leq 5$ tahun, dan tidak pernah memakai kontrasepsi hormonal. ${ }^{16}$

\section{HASIL}

Hasil penelitian menunjukkan prevalensi tumor payudara pada perempuan muda usia 25-39 tahun di Indonesia pada penelitian ini mencapai $8,1 \%$. Perempuan usia muda di bawah 40 tahun yang mengalami menarche sebelum 12 tahun hanya sebanyak $6,4 \%$. Berdasarkan status perkawinan, menunjukkan bahwa sebagian besar $(95,2 \%)$ status perkawinan perempuan usia muda di Indonesia adalah kawin. Berdasarkan distribusi usia pertama melahirkan, terdapat $87,9 \%$ yang melahirkan di usia kurang dari sama dengan 30 tahun. Kemudian diikuti dengan $9,4 \%$ yang nullipara atau tidak melahirkan, dan 2,7\% yang melahirkan di usia lebih dari 30 tahun. Berdasarkan riwayat

Tabel 1. Hasil Analisis Univariat

\begin{tabular}{|c|c|c|}
\hline Variabel & $\mathbf{n}$ & $\%$ \\
\hline \multicolumn{3}{|l|}{ Tumor Payudara } \\
\hline Positif & 1.210 & 8,1 \\
\hline Negatif & 13.681 & 91,9 \\
\hline \multicolumn{3}{|l|}{ Usia } \\
\hline $25-29$ tahun & 3.293 & 22,1 \\
\hline $30-34$ tahun & 5.156 & 34,7 \\
\hline $35-39$ tahun & 6.433 & 43,2 \\
\hline \multicolumn{3}{|l|}{ Pendidikan } \\
\hline Tinggi & 8.338 & 56,0 \\
\hline Rendah & 6.553 & 44,0 \\
\hline \multicolumn{3}{|l|}{ Pekerjaan } \\
\hline Berkerja & 5.068 & 34,0 \\
\hline Tidak berkerja & 9.823 & 66,0 \\
\hline \multicolumn{3}{|l|}{ Usia Menarche } \\
\hline$<12$ tahun & 950 & 6,4 \\
\hline$\geq 12$ tahun & 13.941 & 93,6 \\
\hline \multicolumn{3}{|l|}{ Status perkawinan } \\
\hline Tidak kawin & 714 & 4,8 \\
\hline Kawin & 14.177 & 95,2 \\
\hline \multicolumn{3}{|l|}{ Usia Pertama Melahirkan } \\
\hline Nullipara/tidak pernah melahirkan & 1.397 & 9,4 \\
\hline$>30$ tahun & 411 & 2,8 \\
\hline$\leq 30$ tahun & 13.083 & 87,9 \\
\hline \multicolumn{3}{|l|}{ Riwayat Menyusui } \\
\hline Tidak menyusui & 2.680 & 18,0 \\
\hline Menyusui & 12.211 & 82,0 \\
\hline \multicolumn{3}{|l|}{ Riwayat Kontrasepsi Hormonal } \\
\hline$\geq 5$ tahun & 3.924 & 26,4 \\
\hline$<5$ tahun & 5.968 & 40,1 \\
\hline Tidak pernah memakai & 4.999 & 33,6 \\
\hline
\end{tabular}

Sumber: Kementerian Kesehatan RI, 2016 
Tabel 2. Hasil Analisis Bivariat

\begin{tabular}{|c|c|c|c|c|c|c|c|}
\hline \multirow{3}{*}{ Variabel } & \multicolumn{7}{|c|}{ Tumor Payudara } \\
\hline & \multicolumn{2}{|c|}{ Positif } & \multicolumn{2}{|c|}{ Negatif } & \multirow{2}{*}{ p-value } & \multirow{2}{*}{ ORcrude } & \multirow{2}{*}{$95 \% \mathrm{CI}$} \\
\hline & $\mathrm{n}$ & $\%$ & $\mathbf{n}$ & $\%$ & & & \\
\hline \multicolumn{8}{|l|}{ Usia } \\
\hline $25-29$ tahun & 280 & 8,5 & 3.013 & 91,5 & 0,908 & 1,01 & $0,89-1,17$ \\
\hline $30-34$ tahun & 388 & 7,5 & 4.777 & 92,5 & 0,074 & 0,88 & $0,77-1,01$ \\
\hline $35-39$ tahun & 542 & 8,4 & 5.891 & 91,6 & Ref & 1 & Ref \\
\hline \multicolumn{8}{|l|}{ Pendidikan } \\
\hline Tinggi & 712 & 8,5 & 7.626 & 91,5 & $0,037^{*}$ & 1,14 & $1,01-1,28$ \\
\hline Rendah & 498 & 7,6 & 6.055 & 92,4 & Ref & 1 & \\
\hline Pekerjaan & & & & & & & $1,00-1,28$ \\
\hline Berkerja & 443 & 8,7 & 4.625 & 91,3 & $0,049^{*}$ & 1,13 & \\
\hline Tidak berkerja & 767 & 7,8 & 9.056 & 92,2 & Ref & 1 & $1,04-1,61$ \\
\hline \multicolumn{8}{|l|}{ Usia Menarche } \\
\hline$<12$ tahun & 96 & 10,1 & 854 & 89,9 & $0,021^{*}$ & 1,29 & $1,24-1,98$ \\
\hline$\geq 12$ tahun & 1.141 & 8,0 & 12.827 & 92,0 & & 1 & \\
\hline \multicolumn{8}{|l|}{ Status perkawinan } \\
\hline Tidak kawin & 85 & 11,9 & 629 & 88,1 & $0,000^{*}$ & 1,57 & $1,32-1,87$ \\
\hline Kawin & 1.125 & 7,9 & 13.052 & 92,1 & & 1 & \\
\hline Usia Pertama Melahirkan & & & & & & & $0,89-1,76$ \\
\hline Nullipara/tidak pernah melahirkan & 162 & 11,6 & 1.235 & 88,4 & $0,000^{*}$ & 1,57 & \\
\hline$>30$ tahun & 39 & 9,5 & 372 & 90,5 & 0,187 & 1,26 & \\
\hline$\leq 30$ tahun & 1.009 & 7,7 & 12.074 & 92,3 & & 1 & $1,24-1,64$ \\
\hline \multicolumn{8}{|l|}{ Riwayat Menyusui } \\
\hline Tidak menyusui & 281 & 10,5 & 2.399 & 89,5 & $0,000^{*}$ & 1,42 & \\
\hline Menyusui & 929 & 7,6 & 11.282 & 92,4 & & 1 & \\
\hline \multicolumn{8}{|l|}{ Riwayat Kontrasepsi Hormonal } \\
\hline$\geq 5$ tahun & 272 & 6,9 & 3.652 & 93,1 & $0,000^{*}$ & 0,72 & $0,69-0,88$ \\
\hline$<5$ tahun & 470 & 7,9 & 5.498 & 92,1 & & 0,83 & $0,72-0,95$ \\
\hline Tidak pernah memakai & 468 & 9,4 & 4.531 & 90,6 & $0,006^{*}$ & 1 & \\
\hline
\end{tabular}

Keterangan: "signifikan secara statistik nilai $p$-value $<0,05$

Sumber: Kementerian Kesehatan RI, 2016

menyusui, menunjukkan bahwa $82 \%$ perempuan usia di bawah 40 tahun di Indonesia pernah menyusui. Distribusi riwayat penggunaan kontrasepsi perempuan usia muda di bawah 40 tahun menunjukkan bahwa sebagian besar (40,1\%) perempuan usia muda di bawah 40 tahun pernah menggunakan kontrasepsi hormonal berupa pil $\mathrm{KB}$, suntik $\mathrm{KB}$, dan susuk (implan) selama kurang dari 5 tahun. Sedangkan, 26,4\% menggunakan kontrasepsi hormonal selama 5 tahun lebih. Dan sisanya $(33,6 \%)$ tidak pernah menggunakan alat kontrasepsi hormonal (Tabel 1).

Hasil analisis multivariat dilakukan setelah melakukan analisis bivariat dengan menganalisis variabel yang memiliki $p$-value $<0,25$. Pada analisis ini variabel yang dinilai berhubungan secara statistik yaitu pendidikan, pekerjaan, usia menar- che, status perkawinan, usia pertama melahirkan (Nullipara/tidak pernah melahirkan), riwayat menyusui, dan riwayat kontraspeti hormonal $(>=5$ tahun dan $<5$ tahun) (Tabel 2). Semua variabel independen masuk dalam analisis multivariat. Berdasarkan hasil analisis multivariat yang ditunjukkan pada tabel 3, faktor yang paling berpengaruh terhadap kejadian tumor payudara pada perempuan usia muda di Indonesia yaitu usia menarche, status perkawinan, riwayat menyusui, dan riwayat penggunaan kontrasepsi hormonal 5 tahun lebih. Responden yang mengalami menstruasi sebelum usia 12 tahun berisiko 1,269 kali terkena tumor payudara. Perempuan yang tidak menikah memiliki risiko 1,353 kali terkena tumor dibandingkan perempuan yang menikah. Riwayat tidak pernah menyusui menyebabkan risiko 1,295 kali terkena 
Tabel 3. Model Akhir

\begin{tabular}{lccc}
\hline \multicolumn{1}{c}{ Variabel } & p-value & ORadjusted & 95\% CI \\
\hline Menarche & $0,034^{*}$ & 1,27 & $1,02-1,58$ \\
Status Perkawinan & $0,014^{*}$ & 1,35 & $1,06-1,72$ \\
Riwayat Menyusui & $0,00^{*}$ & 1,29 & $1,12-1,50$ \\
Riwayat Kontrasepsi (1) & $0,004^{*}$ & 1,27 & $1,08-1,49$ \\
Riwayat Kontrasepsi (2) & 0,132 & 1,11 & $0,97-1,28$ \\
\hline
\end{tabular}

Keterangan: *signifikan secara statistik nilai $p$-value $<0,05$

Sumber: Kementerian Kesehatan RI, 2016

tumor payudara. Menggunakan kontrasepsi hormonal selama 5 tahun lebih memiliki risiko 1,265 kali terkena tumor payudara dibandingkan tidak pernah memakai kontrasepsi hormonal.

\section{PEMBAHASAN}

Berbagai faktor risiko dapat mempengaruhi kejadian tumor payudara, seperti riwayat kanker pada keluarga, gaya hidup, pendapatan, status gizi, paparan lingkungan, riwayat reproduksi, dan konsumsi. Namun, pada penelitian ini, peneliti hanya meneliti hubungan faktor risiko riwayat reproduksi dengan kejadian tumor payudara karena adanya keterbatasan permintaan data. Hal ini juga dimaksudkan agar penelitian ini menjadi lebih fokus. Response rate responden yang diperiksa Sadanis di Riset PTM 2016 adalah 62,5\%. Beberapa alasan responden tidak melakukan pemeriksaan Sadanis karena tidak berada di tempat, sedang bekerja, memiliki kesibukan lain, menolak untuk diperiksa, dan lain-lain. Sehingga, peneliti perlu berhati-hati dalam menggeneralisasi prevalensi yang ada.

Berdasarkan hasil analisis, faktor-faktor yang mempengaruhi kejadian tumor payudara pada perempuan usia muda di Indonesia yaitu usia menarche, status perkawinan, riwayat menyusui, dan riwayat penggunaan kontrasepsi hormonal 5 tahun lebih.

Tumor payudara saat ini tidak hanya diderita oleh wanita usia menopause (40 tahun ke atas), tetapi juga mulai menjadi masalah ketika perempuan di usia muda. Sebanyak 11.000 , perempuan di Amerika Serikat bawah 40 tahun terdiagnosis kanker payudara. Angka itu setara dengan 4,7\% hingga 4,9\% dari jumlah kasus tumor payudara. ${ }^{17}$ Prevalensi tumor payudara pada perempuan muda usia 25-39 tahun di Indonesia pada penelitian ini mencapai $8,1 \%$ menunjukkan bahwa proporsi tumor payudara pada usia muda di Indonesia lebih tinggi daripada di negara barat yang cenderung lebih maju.

Uji statistik multivariat menunjukkan bahwa terdapat hubungan bermakna antara usia menarche dan kejadian tumor payudara pada perempuan usia muda di bawah 40 tahun di Indonesia. Hasil penelitian ini sesuai dengan hasil penelitian yang telah dilakukan oleh Dewi dan Hendrati bahwa usia menarche memiliki hubungan yang bermakna terhadap kejadian tumor ganas payudara pada perempuan di RSUD Dr. Soetomo pada tahun 2013 dengan $\mathrm{OR}=3,492 .{ }^{12}$ Menunjukkan bahwa perempuan yang mengalami menstruasi sebelum 12 tahun lebih berisiko untuk terkena tumor payudara dibandingkan perempuan yang mengalami menstruasi pada usia 12 tahun atau lebih. ${ }^{12,13}$

Pengaruh usia menarche terhadap tumor payudara berhubungan dengan lama paparan hormon terhadap tubuh. Usia menarche yang dini pada seorang perempuan dapat disebabkan oleh berbagai hal, yaitu dipengaruhi oleh faktor genetik, faktor lingkungan, dan faktor gaya hidup yang dapat memicu terjadinya menarche dini. Saat ini, telah terjadi pergeseran usia menarche yang cenderung terjadi lebih awal karena adanya perubahan gaya hidup dan pola konsumsi. ${ }^{18}$ Perempuan yang mengalami menstruasi lebih awal dari pada umumnya, akan mendapatkan paparan hormon estrogen dan progesteron lebih lama. Sehingga berpengaruh terhadap proliferasi jaringan, terutama jaringan payudara.

Berdasarkan analisis, terdapat hubungan yang signifikan antara status perkawinan dengan kejadian tumor payudara. Hasil penelitian ini sesuai dengan penelitian Pratiwi, Sety, dan Tinayang menunjukkan bahwa terdapat hubungan bermakna antara status perkawinan dan kejadian 
tumor payudara Fibroadenoma Mammae (FAM) dengan $\mathrm{OR}=2,889 .{ }^{19}$ Angka tersebut menunjukkan bahwa perempuan yang tidak kawin berisiko 2,889 kali terkena fibroadenoma mammae daripada yang memiliki status kawin. Menurut Hinyard perempuan yang belum menikah/tidak menikah lebih mungkin untuk terkena penyakit yang lebih lanjut dan memiliki risiko kematian yang lebih tinggi karena kanker payudara. ${ }^{20}$ Penelitian Kvikstad dan Vatten juga menunjukkan risiko kanker payudara sebesar 1,11 lebih tinggi terjadi pada perempuan yang tidak menikah di Norwegia. ${ }^{21}$ Meskipun, belum ada bukti yang tepat yang menunjukkan alasan protektif perkawinan, namun status perkawinan berpengaruh pada kejadian kehamilan dan aktivitas menyusui yang berpengaruh pada pengaturan hormonal pada perempuan.

Selanjutnya, terdapat hubungan secara statistik antara riwayat menyusui dengan tumor payudara. Perempuan yang tidak pernah menyusui berisiko terkena tumor payudara 1,295 kali dibandingkan perempuan yang pernah menyusui. Penelitian ini sesuai dengan penelitian Rianti et $a l$, yang membuktikan bahwa ada hubungan riwayat menyusui dengan tumor ganas payudara di RS. Dharmais Jakarta dengan OR 2,2.22 Penelitian Nasution dan Asfriyanti juga membuktikan bahwa terdapat hubungan antara status menyusui dan kejadian tumor ganas payudara dengan OR sebesar 8,360. Perempuan yang menyusui kurang dari 6 bulan berisiko 8,360 kali mendapatkan tumor ganas payudara dibanding perempuan yang menyusui 6 bulan atau lebih. $^{13}$

Menyusui menjadi faktor yang protektif terhadap kejadian tumor payudara. Hubungan menyusui terhadap proteksi risiko tumor payudara masih kurang dapat dijelaskan, namun dapat dihubungkan dengan siklus hormonal kehamilan dan menyusui. Jose Russo dan irma H. Russo melakukan perbandingan genetik antara perempuan yang pernah melahirkan dan tidak pernah melahirkan dan menyusui. ${ }^{23}$ Penelitian tersebut menunjukkan bahwa perempuan yang pernah melahirkan dan menyusui memiliki ekspresi gen unik yang mengekspresikan pola diferensiasi sel yang berhubungan dengan gen apoptosis pada proliferasi berlebihan.

Kadar hormon estrogen dan progesteron yang tinggi selama masa kehamilan akan menurun drastis setelah melahirkan karena mekanisme menyusui. Menyusui dapat membuat kadar estrogen dan progesteron akan menurun sehingga mengurangi pengaruh hormon tersebut terhadap proliferasi jaringan di payudara. Menurunnya kadar hormon estrogen dan hormon progesteron dalam darah selama menyusui akan mengurangi pengaruh hormon tersebut terhadap proses proliferasi jaringan termasuk jaringan payudara.

Riwayat penggunaan kontrasepsi dapat memprediksi kejadian tumor payudara pada perempuan usia muda di bawah 40 tahun di Indonesia. Perempuan yang menggunakan kontrasepsi hormonal selama 5 tahun atau lebih berisiko 1,265 kali terkena tumor payudara dibandingkan perempuan yang tidak pernah menggunakan kontrasepsi hormonal. Hal ini sesuai dengan beberapa penelitian yang menunjukkan adanya hubungan prediktif antara penggunaan kontrasepsi dengan kejadian tumor payudara. Penelitian yang dilakukan oleh Dewi diperoleh hasil bahwa pemakaian alat kontrasepsi hormonal memiliki hubungan yang signifikan terhadap kejadian tumor ganas payudara pada perempuan di RSUD Dr. Soetomo pada tahun 2013 ( $p$-value $=0,028)$ dengan $\mathrm{OR}=3,266 .{ }^{12}$ Perempuan yang pernah memakai kontrasepsi hormonal $\geq 5$ tahun berisiko 3,266 kali terkena tumor ganas payudara dibandingkan dengan perempuan yang kurang dari $<5$ tahun. Penelitian Sihombing, juga menunjukkan adanya hubungan antara pemakaian kontrasepsi hormonal dan tumor payudara dengan OR sebesar 2,76. ${ }^{16}$

Hubungan patofisiologi kontrasepsi hormonal dan tumor payudara adalah kandungan estrogen dan progesteron yang ada dalam kontrasepsi. Penggunaan kontrasepsi hormonal akan meningkatkan pajanan hormon estrogen dan progesteron tubuh, terutama pada payudara. Hormon estrogen sangat berpengaruh terhadap pertumbuhan dan perkembangan jaringan pada payudara. Sehingga pajanan yang lama dapat menyebabkan proliferasi yang berlebihan pada jaringan payudara. Namun, meskipun begitu, pengaruh kontrasepsi oral dan kejadian tumor payudara masih diperdebatkan. Oleh karena hal tersebut dipengaruhi oleh kadar yang dikonsumsi, jenis kandungan hormon kontrasepsi, dan usia saat memulai kontrasepsi. ${ }^{12}$ 
Beberapa aspek mengenai metode penelitian dan sampel penelitian perlu diperhatikan karena mungkin dapat mempengaruhi hasil penelitian. Penelitian ini menggunakan desain studi cross sectional di mana pengukuran pajanan dan outcome dilakukan pada waktu bersamaan. Penelitian ini menggunakan data sekunder dari Riset PTM 2016 sehingga peneliti tidak memiliki kendali terhadap proses pengambilan data dan manajemen data. Pengambilan data yang dilakukan Riset PTM 2016 yaitu dengan wawancara dan dilanjutkan dengan pemeriksaan Sadanis di Puskesmas setempat. Informasi mengenai riwayat reproduksi seperti usia menarche dan lama penggunaan kontrasepsi diperoleh hanya berdasarkan daya ingat responden. Bukan berasal dari catatan medis maupun catatan pribadi responden. Hal tersebut dapat mengakibatkan penilaian risiko variabel yang ada menjadi underestimate atau overestimate. Dalam penelitian ini pemeriksaan tumor payudara hanya menggunakan metode clinical breast examination atau Sadanis. Sedangkan untuk menegakkan diagnosis tumor payudara harus menggunakan diagnosis patologi anatomi. Sehingga dalam penelitian ini, kasus tumor payudara bisa saja bukan benarbenar tumor payudara dan dapat menjadikan overestimate kasus tumor payudara dalam penelitian ini.

\section{KESIMPULAN DAN SARAN}

Berdasarkan hasil penelitan yang dilakukan, dapat disimpulkan bahwa faktor-faktor yang dapat memprediksi kejadian tumor payudara pada perempuan usia muda di Indonesia tahun 2016 adalah usia menarche, status perkawinan, riwayat menyusui, dan riwayat pemakaian kontrasepsi hormonal. Perempuan yang mengalami menarche sebelum usia 12 tahun, berstatus tidak menikah, tidak pernah menyusui, atau menggunakan kontrasepsi hormonal 5 tahun lebih meningkatkan risiko kejadian tumor payudara.

Perempuan usia muda di bawah 40 tahun sebaiknya mulai sadar akan risiko tumor payudara dan menghindari faktor risiko tumor payudara, melakukan Sadari, dan melakukan Sadanis jika merasakan perubahan pada payudara di fasilitas pelayanan kesehatan. Menarche dini dapat meningkatkan risiko tumor payudara, sehingga perempuan perlu mencegah terjadinya menarche dini dengan menerapkan gaya hidup yang sehat seperti menjaga pola konsumsi, mengurangi makanan cepat saji, dan menjaga aktivitas fisik. Selain itu, perempuan perlu melakukan konseling kesehatan reproduksi dan mengkonsultasikan usia pernikahan yang sesuai dengan tenaga kesehatan. Ibu yang melahirkan, dianjurkan memberikan ASI kepada bayi untuk menyeimbangkan hormon estrogen dalam tubuh karena dapat mengurangi risiko tumor payudara. Adapun, perempuan sebaiknya bijak dalam menggunakan alat kontrasepsi hormonal dengan berkonsultasi dengan petugas kesehatan untuk menentukan jenis dan durasi pemakaian kontrasepsi.

\section{UCAPAN TERIMA KASIH}

Peneliti mengucapkan terima kasih kepada Badan Penelitian dan Pengembangan Kesehatan Kementerian Kesehatan RI yang telah mengijinkan peneliti untuk menggunakan data Riset PTM 2016.

\section{DAFTAR PUSTAKA}

1. Riley T. Benign Breast Disease. Physician Assistant Clinics. 2018:3(3);363-371.

2. Sharma GN, Dave R, Sanadya J, Shama P, Sharma KK. Various Types and Management of Breast Cancer: An Overview. Journal of Advanced Pharmaceutical Technology \& Research. 2010:1(2);109-126.

3. WHO. Guidelines for Management of Breast Cancer. Regional Office for the Eastern Mediterranean. WHO; 2006.

4. Anyikam A, Nzegwu MA, Ozumba BC, Okoye I, Olusina DB. Benign Breast Lesions in Eastern Nigeria. Saudi Medical Journal. 2008:29(2);241-244

5. Kotepui M, Piwkham D, Chupeerach C, Songsri A, Charoenkijkajorn L. Epidemiology and Histopathology of Benign Breast Diseases and Breast Cancer in Southern Thailand. European Journal of Gyneacological Oncology. 2014:35(6);670-675.

6. Kementerian Kesehatan RI. Data Program Deteksi Dini Sadanis dan IVA. Jakarta: Kementerian Kesehatan: Subdit Penyakit Kanker dan Kelainan Darah; 2018.

7. Cardoso, Loibl, Pagani, Graziottin, Panizza, Martincich, et al. The European Society of 
Breast Cancer Specialists Recommendations for the Management of Young Women with Breast Cancer. European Journal of Cancer. 2012:48(2);3355-3377.

8. Azim HJ, Partridge A. Biology of Breast Cancer in Young Women. Breast Cancer Research. 2014:16(4);1-9.

9. Kementerian Kesehatan RI. Laporan Riset Penyakit Tidak Menular: Tumor Payudara dan Lesi Prakanker Serviks. Jakarta: Badan Penelitian dan Pengembangan Kesehatan; 2016.

10. Castells X, Domingo L, Corominas J, Torá-Rocamora I, Quintana M, Baré M, et al. Breast Cancer Risk After Diagnosis by Screening Mammography of Nonproliferative or Proliferative Benign Breast Disease: A Study from A Population-based Screening Program. Breast Cancer Research and Treatment. 2015:149(1);237-244.

11. Murti B. Prinsip dan Metode Riset Epidemiologi. Yogyakarta: UGM; 1997.

12. Dewi GAT, Hendrati LY. Analisis Risiko Kanker Payudara Berdasar Riwayat Pemakaian Kontrasepsi Hormonal dan Usia Menarche. Jurnal Berkala Epidemiologi. 2015:3(1);12-23

13. Nasution WM, Asfriyanti. The Analysis of Breast Cancer Causes at General Hospital Dr. Pringadi Medan. Advances in Health Sciences Research. 2017:9(2);43-47.

14. Bidgoli S, Eftekhari T. Role of Exogenous and Endogenous Sources of Estrogen on the Incidence of Breast Fibroadenoma: Casecontrol Study in Iran. Asian Pacific Journal Cancer Prevention. 2011:12(5);1289-1293.

15. Lambe M, Hsieh C, Trichopoulos D, Ekbom A, Pavia M, Adami H. Transient Increase in the Risk of Breast Cancer after Giving Birth. New England Journal of Medicine. 1994: 331(1);5-9.

16. Sihombing M, Sapardin A. Faktor Risiko Tumor Payudara pada Perempuan Umur 25-65 Tahun di Lima Kelurahan Kecamatan Bogor Tengah. Indonesian Journal of Reproductive Health. 2014:5(3);175-184.

17. American Cancer Society. Breast Cancer Facts \& Figure 2013-2014. Atlanta: American Cancer Society; 2014.

18. Anggraini M. Hubungan Antara Usia Saat Timbulnya Menarche dengan Usia Saat Terjadinya Menopause Wanita di Kecamatan Kartasura. Jurnal Unimus. 2008:5(1);203209.

19. Pratiwi H, Sety L, Tina L. Analisis Faktor Risiko Kejadian Penyakit Fibroadenoma Mammae (FAM) di Rumah Sakit Umum Daerah Bahteramas Provinsi Sulawesi Tenggara Tahun 2017. Jurnal Ilmiah Mahasiswa Kesehatan Masyarakat. 2017:3(2);2-11.

20. Hinyard L, Schwartz T. Marital Status, Stage of Diagnosis, and Survival in Younger Women with Breast Cancer. Value in Health Journal. 2016:19(3): A169.

21. Kvikstad A, Vatten LJ. Cancer Risk and Prognosis in Norway: Comparing Women in Their First Marriage with Women Who Have Never Married. Journal of Epidemiology and Community Health. 1996:50(1);51-55.

22. Rianti E, Tirtawati GA, Novita H. Faktor-Faktor yang Berhubungan dengan Risiko Kanker Payudara Wanita. Journal Health Quality. 2012:3(1);10-23.

23. Russo J, Russo I. Breast Development, Hormones, and Cancer. Advances in Experimental Medicine and Biology. 2008:630;52-56. 